\title{
Becoming Critical: In-service Teachers' Perspectives on Multicultural Education
}

\author{
Roland G. Pourdavood and Meng Yan \\ Cleveland State University (CSU) \\ Cleveland, Ohio, USA
}

\begin{abstract}
Many in-service teachers take a passive position regarding multicultural issues such as race, class, ethnicity, socio-economic, religion, gender, and sexual orientation. This passive position impacts classroom dynamics and has social justice consequences. The present qualitative study focuses on 12 in-service teachers' perspectives on multicultural issues. It describes the transformation of their perspectives and practices as they take a semester-long course on diversity. Data sources include the participating teachers' written reflections on assigned readings, classroom discussions and activities, paper presentations, instructor's field notes, and the teachers' final implementation papers. The findings of the study suggest that classroom activities and discussions provided teachers with opportunities to critically reflect on who they are and make changes in their perspectives and practices. Also, the study discusses the vital role of classroom social norms established by the instructor and the participating teachers as a form of praxis. This step is crucial for creating caring communities relative to cross-cultural interaction and individual transformation, which in turn has social justice implications in terms of rethinking teaching and learning as well as school reform.
\end{abstract}

Keywords: multicultural education; teachers' critical reflection; teachers' transformation; school reform; social justice

\section{Introduction}

As a result of the increasing number of immigrants in the United States, schools across the country admit students from different racial and cultural backgrounds every year. According to the National Center for Educational Statistics (2016), the 2014-2015 academic year was a turning point for major changes in the demographics of students. For the first time in the United States, students of color (50.3 percent) outnumbered their White peers (49.7 percent) in public schools, and this trend is expected to continue (Grant, Lee, \& Lyttle, 2018). By 2023 , students of color are expected to account for 55 percent of the public school populations (National Center for Educational Statistics, 2016). Besides, about 20 percent of school-aged children live in poverty, 13 percent of the students in public schools have various disabilities (Gollnick \& Chinn, 2017), and many are 
English language learners. While in contrast, the demographics of teachers in public schools are not keeping pace, with White teachers comprising up to 82 percent and female 76 percent (Hussar \& Bailey, 2013).

The majority of teachers continue to be predominantly Caucasian, middle class and English monolingual speakers (Nieto, 2000b; Sleeter, 1994), and many new entrants to the field of teaching lack the knowledge of the experiences and resources of culturally and linguistically diverse student populations. In this sense, they are in vulnerable conditions facing the challenging issues such as racism, sexual orientations, and social inequality (Sleeter, 2001), which raises an essential question about teacher preparation and professional competence to effectively educate the students in those diverse classrooms (Grant, Lee, \& Lyttle, 2018). It is generally agreed that good teachers need to have content knowledge (Hill \& Ball, 2004), pedagogical content knowledge (Shulman, 1986), and knowledge of students and their communities (Ladson-Billings, 1995a; 1995b). Moreover, teachers also need a deep understanding of social movements, history, culture, political economy, and local and global socio-political forces that influence students' lives as well as special tendencies of social change to develop critical thinking (Gutstein, 2006a).

Except for the mismatch between the demographics of teachers and students, majority of the curricula, textbooks, and teaching materials focus on mainstream Americans, the dominant cultural group (Banks, 1994; Nieto, 2000a, Sleeter \& Grant, 1999), with little attention to most of the diverse groups. In addition, the educational strategies practiced in schools are based on the values and beliefs of mainstream culture (Darder, 1991), which severely marginalizes the less dominant groups. Gay (2003) presents that those racially or culturally diverse students do not find schooling exciting or inviting and they feel unwelcome, insignificant, and alienated more often because what is being taught has no direct value to them and does not reflect who they are. Studies show that students are more successful when they can see their own experiences mirrored in the school curriculum and make personal connections to the content being taught (Hrabowski \& Robbi, 2002; Salako \& Adu, 2013). A major factor in establishing educational relevance for these students is cultural similarity and responsiveness (Bruner, 1996; Wlodkowski \& Ginsberg, 1995). Research indicated that when teachers use culturally responsive pedagogy, the academic achievement of minority students increases (Au, 2011; Ladson-Billings, 1995a; \& Moll et al, 1992). Banks (1994) contends that "a curriculum that focuses on the experiences of mainstream Americans and largely ignores the experiences, cultures, and histories of other racial, ethnic, cultural, and religious groups has negative consequences for both mainstream American students and students of color. A mainstream-centric curriculum is one major way in which racism and ethnocentrism are reinforced and perpetuated in the schools and also in society at large" (p. 229).

Multicultural education arose at the historic moment to provide educators with a platform for working with the diverse school populations and achieving justice within societies marked by inequalities based on race, ethnicity, socioeconomic status, language, gender, and religion (Banks, 2004). The culturally and racially diverse student populations require educators to be cognizant of the differences among them and integrate diversity content throughout the curriculum to 
successfully implement multicultural education, thereby helping to improve their performance and promote their development. Smith, Constantine, Dunn, Dinehart, and Montoya (2006) conducted two meta-analyses on 82 studies of multicultural education, the findings of which demonstrate a positive effect of multicultural education on a wide variety of participants and study characteristics. Apart from narrowing the achievement gap among students of different races, Ameny-Dixon (2004) and Gay (2003) conclude that multicultural education is beneficial in many other ways-it fosters intellectual and moral development of all humans, promotes positive relations between people, and helps to reduce prejudice. Moreover, inclusive curriculum can help deepen students' understanding of important social issues and prepare them to be critical and active participants in a democracy (Gutstein \& Peterson, 2013). Freire (2000) contends that multicultural education helps achieve the pursuit of education as emancipatory.

However, due to ideological and political resistance, high-stakes testing, teacher accountability, and most importantly, teachers' lack of sufficient skills and knowledge of their students' cultures, any changes towards multiculturalism have been difficult (Alismail, 2016). Sue, Arredondo, and McDavis (1992) hold that three levels of understanding are required for multicultural competences, namely awareness, knowledge, and skills. Yet these competencies are not easy to acquire (Garcia \& Pugh, 1992). Hence, teacher training is an important and urgent approach to helping educators improve their capability of implementing and enhancing multicultural education. Villegas and Lucas (2002) argue that one of the critical goals of teacher education programs should be to develop teachers into "agents of change" who challenge and transform institutional and societal inequalities reproduced in schools.

Based on the complexity of what goes on in the day-to-day classroom, teachers need to be aware, prepared, and adaptive to meet the demands of today's classrooms. The purpose of this research study is to examine in-service teachers' prior perspectives on multicultural issues and the transformation of their perspectives and practices as they engage in classroom discussions and activities. The primary research question is: how may a semester-long course on diversity provide in-service teachers opportunities to examine their prior perspectives on multicultural issues and transform their perspectives and practices? This study contributes to two major areas of the current research on multicultural issues. The first area of contribution is the vital role of critical reflection as a form of praxis for professional transformation. By focusing on who they are, teachers can better understand their own biases and limitations. This critical reflection helps the teachers cross the boundary of their own familiar culture and enter into other unfamiliar territories (e.g. professional transformation). The second area is creating a safe, fair, and caring classroom community, which is crucial for establishing a viable and adaptable classroom where critical thinking is encouraged by the teacher. Establishing classroom social norms conducive to learning has social justice implications for reaching out to all students in a multicultural classroom. 


\section{Literature Review}

The historical roots of multicultural education date back to the Civil Rights Movement in 1962 (Banks, 2013). During the 1960s and 1970s, various oppressed groups demanded freedom, social justice, political and educational rights. They demanded that public schools include their histories, cultures and other ethnic content into curriculum, and provide equal education and employment opportunities, thereby providing minority children with role models. These actions helped to determine multicultural education's early idealization (Gay, 1997).

In the 1980s, one of the pioneers of multicultural education, James A. Banks worked to examine schools as social systems from a multicultural perspective (Alismail, 2016). Banks (1989) defines multiculturalism as "a philosophical position and movement that deems that the gender, ethnic, racial, and cultural diversity of a pluralistic society should be reflected in all of the institutionalized structures of educational institutions, including the staff, the norms, the values, the curriculum, and the student body" (p. 11). This philosophical concept is the basis of his multicultural education thoughts, and its goal is that all children, regardless of race, social class, gender, and language, should have equal access to education (Alismail, 2016). Therefore, multicultural education, as an ideal and movement, was the purpose and means to realize this philosophical concept (Banks, 1989). By the late 1980s, research of emerging scholars such as Carl Grant, Christine Sleeter, Geneva Gay, and Sonia Nieto laid a solid foundation for early multicultural education. By providing a profound framework aimed at promoting social change and equal access to education, they developed educational models based on equal opportunities, social justice and critical thinking (Banks, 2001).

Banks and Banks (2001) define multicultural education as "an idea, an educational reform movement, and a process whose major goal is to change the structure of educational institutions so that male and female students, exceptional students, and students who are members of diverse racial, ethnic, language, and cultural groups will have an equal chance to achieve academically in school" (p. 1). He describes five dimensions of multicultural education, namely content integration; knowledge construction; prejudice reduction; equity pedagogy; and empowering school culture and social structure (Banks, 1993; 1994). Banks (1999) states that a multicultural school should be a place where responsive teachers and school administrators treat all the students positively, show respect for the students' first languages and dialects, and expect high with care. He continues that school curriculum and instructional materials should reflect the experiences, cultures, and histories of all racial, ethnic, cultural, and religious groups as well as of both genders; the assessment and testing procedures are culturally sensitive, allowing students of color to account for a certain proportion of talented classes; and school counselors show high expectations for diverse students and help them set and achieve positive career goals in a culturally and ethnically diverse school culture.

In the context of globalization, effective teaching requires educators not just know about the students, their communities, and their histories, but their experiences before coming to the United States, which include the movements, 
politics, cultural traditions, and conflicts from their home countries, and this is essential for creating curricular and teaching culturally relevant practices (Apple, 2011; Apple \& Beane, 2007; Ladson-Billings, 1994). Besides, all teachers need to better understand global realities, think relationally and face the global political, economical, and cultural context to help achieve social justice (Apple, 2011). Apple $(2017 ; 2018)$ calls for critical educators and argues that they should engage in building critically democratic education, thinking about what is being taught, whose knowledge it is, how it became official, who has cultural, social, and economical capital in this society, who benefit from the definitions of legitimate knowledge, what are the overt and hidden effects of education reforms on real people and real communities, as well as what they can do as critical educators and activists to challenge existing educational and social inequalities and to create more socially just curricula and teaching.

To foster moral students and citizens, Noddings (1992, 1995, \& 2008) contends it is necessary that schools establish a moral climate in which caring relations can develop, especially in such an era when there is increasing violence among school children and society while schools only focus on students' academic performance. She thinks good teachers should connect the moral worlds of school and public life to enhance the possibility for the students to live in and promote a caring climate and take a caring attitude into their future career and civil life (Noddings, 2012). Holding that "caring implies a continuous search for competence" (p. 676), Noddings (1995) emphasizes that it is important to organize school curriculum around the theme of care, and suggests educators choose curriculum that contributes to the growth of children as carers.

As Le Roux and Connors (2001) noted, teachers' perceptions and attitudes influence their expectations and treatment of the learners, which may directly impact students and cause them to exhibit either positive or negative attitudes or behaviors. To implement and enhance multicultural education, schools and educators should be culturally responsive, however, some widespread misperceptions hinder educators' and administrators' appreciation of and respect for multicultural education, thus slowing its implementation (D' Souza, 1991; Ford, 2014). One such misconception is that multicultural education is only for minority students and White students do not need to learn about other cultures; another misconception is the view that multicultural education is a movement against the western civilization; and a third one is that multicultural education is divisive and undercuts the unity of the nation (Banks, 1993; Ford, 2014). Literature also shows quite a few issues in the implementation of multicultural education such as resistance from some students, parents, educators, and administrators, lack of teacher training, parent involvement and school funding, as well as the difficulty in helping students with various traumatic backgrounds.

Given this, Banks and Banks (1995), Delpit (1992), Gay (1994), and LadsonBillings (1995a) identified the following variables of school that need to be reformed to promote multicultural education thoughtfully and comprehensively. They include school policy and politics, school culture and hidden curriculum, learning styles of the school, languages, and dialects of the 
school, community participation and input, counseling programs, assessment, and testing procedures, instructional materials, the formalized curriculum and course of study, teaching styles and strategies, and school staff (their attitudes, perceptions, beliefs, and actions).

Although a significant number of studies investigated multicultural education, there is a clear lack of research focusing on how a semester-long in-person education course may provide the in-service teachers with opportunities to transform their perspectives and practices relative to multiculturalism. The transformation of teachers into change agents in their classrooms may be a big step towards mass access and equity in education.

\section{Theoretical Assumption and Context of the Study}

The theoretical assumption of the study is grounded in social constructivist perspective (Cobb, 1994; Cobb, Wood, \& Yackel, 1990, Cobb \& Yeckel, 1996; Guba \& Lincoln, 1994). This perspective is important for understanding and examining teaching practices and underlying world views implicit in actions, stated beliefs, and classroom dynamics. "Human behavior unlike that of physical objects, cannot be understood without references to the meanings and purposes attached by human actors to their activities" (Guba \& Lincoln, 1994, p. 106). Classroom dynamics represent an open system whereby complex interactions and mutual connections prevent the attribution of simple causes to classroom events. According to social constructivism, reality is built individually as well as socially. In this sense, active participation in and contribution to the classroom activities and assignments are necessary conditions for constructive teaching and learning.

This current study was conducted in an American university in the Midwest. The participants included 12 in-service teachers enrolled in a graduate course titled Diversity in Educational Settings during the spring semester of 2019. It was a three-credit-hour course occurring once a week for three hours for a total of 15 weeks. The participating teachers' age varied from 28 to 52, with their teaching experience ranging from 3 to 20 years, and some of them have taught internationally. Also, the grade levels they were certified to teach differed from elementary to high school focusing on different specializations such as early childhood, special education, middle childhood mathematics and science, middle childhood and secondary language arts.

The course focuses on issues related to political ideologies which have a powerful influence on one's views regarding other forms of diversity such as multicultural education, race, ethnicity, sex, social class, religion, exceptionalities, language, and age. The course intends to prepare teachers for the harsh realities of today's schools such as students' various family backgrounds, poverty and its correlates, students with cognitive and emotional issues, apathetic students, poor administration, and schools with low academic standards, which are the issues that the participating teachers may encounter in their schools. In addition, the course examines how diversity, in its many complex forms, is related to all aspects of education. It discusses the role of tolerance in a diverse society and conflict resolution techniques that can minimize prejudice, discrimination, and violence in educational settings. 
Furthermore, the course provides the participating teachers with opportunities to critically examine the relationship between diversity and cultural unity in a democratic society characterized by dynamic changes owing to globalization, cultural turbulence, technological advances, and immigration trends. It examines issues and problems from multiple perspectives, with emphasis on empirical evidence and social justice issues.

The required assignments of the course include discussions on reading reflections; first project "Ethnic History" or "My Story" paper presentation; second project "Current Event" paper presentation; and third project paper "My Plan for Implementing Multicultural Education". The Ethnic History paper presentation is a writing of the participating teachers' ethnic history through a description of their ethnic identity and cultural background. Ideas for the paper include countries of origin, traditions, customs, family stories/jokes, foods, favorite holiday celebrations, expectations regarding education, gender roles, work and family, neighborhoods, language use, dialects, and religious practices. In their writing of Ethnic History Paper, the teachers were guided to include the areas and issues covered in their reading assignments, such as Race and Ethnicity, Gender, Class, Language, Religion, Ability, Geography, and Age. They needed to include their former and current attitudes, beliefs, and values, and were encouraged to identify important issues or situations that had influenced their life, their beliefs and values, their thoughts, and their actions. The participating teachers were also encouraged to reflect on the following questions: Who am I? What kind of teacher am I, or what kind of teacher will I become and why? Is there anything about me that should be my asset as an educator? For the second project, "Current Event", each participating teacher selected a news article on a controversial or debatable topic and presented their selected topics to the class. The articles should be current and focus on multicultural or diversity issues that affect education and our social life. The participating teachers may utilize a variety of resources such as journals, newspapers, the internet, etc. They were expected to thoroughly investigate the topic to answer the $5 \mathrm{~W}$ questions (who, when, where, what, and why) that would relate the article to real-life situations and/or experiences they encountered during their lives. In the third project, "My Plan for Implementing Multicultural Education", the participating teachers focused on their plans for implementing and enhancing multicultural education in the context of their current and/or future educational settings. The teachers were encouraged to use various resources including class notes, class activities and discussions, class video presentations, along with information and materials identified by the instructor.

\section{Methodology}

The present research aims to investigate in-service teachers' perceptions of multicultural education and the change of their perspectives and practices, qualitative research design, therefore, is the most suitable approach in that it is "exploratory in nature" (Hays, \& Singh, 2012, p. 5) and helps researchers to use inductive analysis for answering the research questions. Creswell and Poth (2018) posit that qualitative data could add richness and clues to the complexity 
of our understanding of the in-service teachers' experiences, perceptions, competence, and willingness to implement multicultural education. Similarly, Burton (2012), who researched the ability of certain methods courses to change students' attitudes, suggests that qualitative data could provide valuable information on different factors that influence the change process that occurs in participants, something that quantitative research cannot achieve. In addition, the specific setting of the course on diversity creates a bounded system (Creswell \& Poth, 2018) through which rich data can be collected to understand the effectiveness of the course.

Social constructivism paradigm assumes that in the pursuit of science, there are many contextual perspectives and subjective voices that can mark the truth (Hays \& Singh, 2012). The participating teachers' classroom discussions and activities play a vital role in understanding and interpreting the research. Hence, we believe a constructivist research methodology can best reflect the flow of information as the study evolves. The in-service teachers develop subjective meanings of their perceptions, which are varied and multiple, leading us to look for the complexity of views, and those subjective meanings are negotiated between participants and researchers (Creswell \& Poth, 2018). This paradigm may offer insights as to how in-service teachers construct their ways of understanding meaningful multicultural classroom practices, since research relies much on participants' views of the situation (Creswell \& Poth, 2018).

This qualitative, descriptive, and interpretive research design and methodology is influenced by Guba and Lincoln's $(1994,1989)$ constructivist inquiry. Data sources included the participating teachers' written reflections on assigned readings, classroom discussions and activities, paper presentations, instructor's field notes, and the participating teachers' final implementation papers. These data were compared through a constant comparative method (Guba and Lincoln, 1994; 1989). Simultaneously with data collection, data analysis began with coding which Charmaz (2001) describes as the "critical link" between data collection and meaning interpretation. According to Saldana (2013), a code is " $a$ research generated construct that represents and captures a datum's primary content and essence" (p. 4). The initial codes were vivo and descriptive codes (Saldaña, 2013) which summarized primary topics of the data such as the participating teachers' prior-experiences, challenges they encountered in their work, their views about multicultural education, their future plans, etc. As we moved along to the second cycle of coding, we distilled more specific information from which patterns and themes began to emerge as some repetitive codes appeared naturally such as critical reflection, inclusive teacher, pro-active teacher, caring relationship, etc. As patterns and themes began to emerge, we went back to the participating teachers to ask them how well the ongoing data analysis represented their experience (Hays \& Singh, 2012). Along with the coding process, analytical memos were written to "document and reflect on the coding process and code choices" (Saldaña, 2013, p. 41) which helped achieve researcher reflexivity on the data corpus and at the same time provide documentation and transparency about our methodology. Once coding was completed, important factors were identified as considerations regarding participating teachers' perceptions of and transformation towards multicultural education. 
We triangulated data in three ways. First, we compared multiple data sources for consistency. Second, we conducted conversations with the participating teachers once a week for clarifications of our understanding and interpretations. Third, the researchers analyzed the data independently and they conducted a meeting once a month for compatibility of their interpretations. These three ways of triangulation contributed to the trustworthiness of the data analysis. By providing in-depth analysis as to how and how much the participating teachers' perceptions of multicultural education transform after a semester-long course on diversity, we hope this study can contribute to the research on school reform, policies in teacher education and the improvement of people's attention to courses on diversity.

\section{Search for Meaning}

At the beginning of the semester, the instructor of the course negotiated with the participating teachers regarding his roles and expectations. He clearly communicated with the teachers his role as a facilitator and a member of the classroom community. He stated that he was not there to evaluate or judge the teachers' perspectives or practices. Instead, he was there to understand, describe, and interpret classroom activities and the teachers' perspectives. This honest and open conversation between the instructor and the teachers was a critical step towards establishing democratic and emancipatory classroom social norms.

On the first day of the class, the instructor started sharing his "Ethnic Story". He talked about where he came from, how he came to the United States as a political refugee without being able to speak English. He talked about his country of origin which he escaped from because of political persecution. He talked about the geography of his country of origin, his religion, original language, and his family he had to leave behind because of political activities and the risk of his life. He also talked about his education in the United States. This honest presentation of who he is as an instructor of the course opened the door for the participating teachers to emancipate themselves and talk about their "Ethnic Story" freely and openly. The classroom atmosphere gradually changed into a mood of transforming learning community, and the relationship between the instructor and the participating teachers became collegial. They were communicating on an equal footing, sharing their ideas and information in a conversational manner. For example, a female teacher from a traditional working-class family openly shared her complex family background and upbringing. Married at a very young age, her parents got divorced when she was only eight and her brother six. Soon her mother remarried to her stepfather who had two children with him and they gave birth to another two kids shortly. She said it took her quite a long time to adapt to life with the new family members living in the same house. With neither of her parents well educated, she went to a community college having no idea what to do for her career. Luckily, after spending two years taking random courses in college, she realized her passion for education. She described her first job as follows,

"My first job was the most eye-opening experience I had ever had. I had never been in a room with so many languages and cultures all mixed together. All of my students were immigrants or refugees within their first or second year in the country. Welcoming them on the first day and 
not knowing if they understood me or not, I had no idea what to expect with my new middle school students. My number one goal now is to establish a strong rapport with my students and create a supportive classroom community to help them grow" (Participating Teacher's Ethnic Story).

An African American teacher shared that she grew up in a neighborhood where there were only people of her race and ethnicity, with no children from different communities or economic backgrounds. All she knew about people different from those of her community was what she saw on TV, showing that those who were Caucasian had everything they didn't have. She said that people of color on television were in ghetto, ugly and did not have any goals; while White people had everything-they were cute, stylish and had their life goals. She shared that she didn't know whether those Caucasians also lived in trailer parks or used government assistants. She recalled her first trip to the mall: seeing so many people who looked different from her, she got scared and felt herself not belonging to that place. She felt great when she went to a college that was $1 \%$ black, and that is why she now wants her students to know there are different people outside their neighborhoods.

Another female teacher raised in a rather affluent suburb shared that growing up in a predominantly white community, she was relatively ignorant of cultural differences, the history of other cultures, and the struggles other cultures experienced. From kindergarten through high school, she never had a teacher who was not Caucasian. She said that it was not until high school that she began to realize and truly understand how privileged she was. She described her first job in this way,
"When I got my first teaching job, to say that I was excited was an understatement. My students and I were very different. I was one of the Caucasian women teachers but most of my students were African American with the majority males. I taught in a district where $80 \%$ qualified for free or reduced lunch. The culture in my classroom was very different from what I grew up knowing. The differences between each of the students were astounding as well. I realized that I need to participate effectively in more than my culture" (Participating teacher's Ethnic Story).

The participating teachers shared their stories in an open and honest way. They knew they had support from their instructor and colleagues. This safe environment provided them with the opportunity to share their ideas and information freely and openly. This free flow of information was a step towards crossing the boundary of their own familiar culture and being invited to enter other unfamiliar territories. For example, one of the male participating teachers from Iraq shared a picture of his middle school class and recalled that all but three of the students in the picture died one afternoon when the school was bombed. All the students were in the classroom at that moment. Only three including himself survived because they did not go to school that day. He stressed that this is why he values life and his family greatly. Currently, he is teaching in Middle East and he hopes to become a viable teacher to help children 
in need around the world.

In what follows we will describe several themes emerging from the analysis of data including participating teachers' written reflections on assigned readings, classroom discussions and activities, paper presentations, final implementation papers, instructor's field notes, as well as reflexive and analytical memos. The themes that emerged are as follows:

\section{Importance of critical reflections}

Data analysis reveals that most participating teachers realized the vital role of critical reflection as a form of praxis for professional transformation. The teachers reflected on various aspects of multicultural education. For example, one teacher reflected on people's bias against African American students when she shared her experiences relative to false assumptions. She learned during a training session that many people including teachers had lots of misconceptions about African American students, and she thought how the world views her students would affect the way they see the world. She underlined that her job as a teacher is to show her students this colorful world and let them know that some people may dislike them because of their skin color but their differences are worth celebrating.

Another teacher expressed the importance of self-examination. He said that this course opened his eyes to the seriousness of the issues faced by many of his students. He thought it very important to examine our own motives and feelings. He reflected,

"Even the reflection of negative feelings is what allows us not to get trapped in them. It is terrible to know that we have negative feelings towards others, but once we understand them, we could challenge stereotypes, overcome prejudice, and develop relationships with various people-the multicultural population" (Participating Teacher's Reflection).

By critically examining who they are, they were better situated to understand their own biases and transform their practices. One teacher reflected on the issues of race and gender differences by saying,

"No one ethnic group or race is better than another, but in a society that deems the dominant culture as superior to others, that sometimes is hard to see. We as teachers need to model behavior of tolerance and acceptance of different races and genders. We need to be always aware whether we have any bias based on students' race and gender" (Participating Teacher's Reflection).

He noted that gender differences are extreme due to society's implications for masculine or feminine roles; there is no gender equality in the school building where the curriculum is full of men and their accomplishments with little attention to women in an equal light. He held that teachers should add more content focusing on women who are not mentioned in textbooks, those whose roles need to be exposed for students to learn. The importance of visibility and contribution of marginalized groups along with gender equity became the focus of the classroom discussions. 
Realizing that the curriculum does not accurately represent the students in an average American classroom, participating teachers began to reflect on the limitations of the current curriculum and biases of many textbooks. One of them stated, "When I got more educated and aware of cultural differences, I realized I was lucky to attend a top-rated school but unfortunate to have been taught the Anglo-Saxon based curriculum that has ruled our society for generations" (Teacher's Reflection during Classroom Discussions). Looking back at her own schooling and educational career, she became increasingly cognizant of how sheltered, onesided, and White the curriculum actually was and how ignorant-educated and blind she was to other cultures around her. She began to understand and realize it important for students to see themselves in the curriculum. She stated, "I woke up realizing the importance and critical need for a new, reformed, and culturally appropriate curriculum" (Teacher's Reflection during Classroom Discussions).

Another teacher pointed out that many districts and schools do not seem to be concerned or interested in making any changes. He said,
"Understanding the importance and need for a multicultural curriculum is the first step in actually creating and providing students with access to meaningful education. It is incredibly important for educators to understand that teaching practices not taking into consideration students' cultural backgrounds or validating their cultural identities is another example of how societal and political forces influence schooling" (Participating Teacher's Reflection).

Several participating teachers reflected on the transformation of their perspectives by focusing on their teaching philosophy on the implementation of multicultural education in their classrooms. They held that educators need to be open-minded, aware of and accepting all cultures, religions, languages, disabilities, etc. "Educators are in a position to raise students up by having high expectations and providing the least restrictive environment for each student regardless of their race, ethnicity, socio-economic status, gender, language, or ability" (Teacher's Reflection during Classroom Discussions). The teachers believed that it is educators' responsibility to foster motivation, progress, achievement, as well as a love of learning and that it is educators' obligation to facilitate $21^{\text {st-century }}$ skills such as critical thinking, collaboration, innovation, and cultural literacy. They stressed that their job is to promote empathy, awareness, and integration in the world and that educators are models and advocates for equality, justice, and social changes.

As the course evolved, the participating teachers became more aware of their role in their classrooms and schools as change agents. They expressed their transformed perspectives during the classroom discussions and in their presentation papers. Below we will describe two major aspects of teacher transformation, namely becoming inclusive teachers and taking more pro-active roles in the classroom.

\section{Becoming inclusive teachers}

Analysis of the data led to the observation that the participating teachers attach great importance to inclusiveness. Becoming inclusive teachers to create an 
inclusive classroom is one of the most repetitive codes. It has been mentioned 57 times by the teachers and is the most used description. Almost all of the 12 participants emphasized the notion of inclusiveness and stated that being inclusive is the first step in the implementation and promotion of multicultural education.

One of the teachers held, "The way we educate a child can make or destroy him/her. If we do not value our students individually, acknowledge what they bring to the class community, and celebrate their cultures and interests, we are doing them a disservice" (Teacher's Reflection during Classroom Discussions). He held that students need help to recognize their full potential and find their places in this diverse world; with discrimination pervading our society, teachers need to make it their major goal building an inclusive and supportive classroom community. He stated passionately, "If we truly care about and respect our students, everything will follow. Use students' experiences and backgrounds to enhance the learning environment and place students first every day, and they will really shine" (Teacher's Reflection during Classroom Discussions).

Another teacher stressed the importance of caring and love in an inclusive classroom. She stated,

"No two children are identical, and children need to know that they are loved and accepted the way they are. Every child deserves a chance to get a great education. We as educators must do everything we can to promote an inclusive classroom and provide opportunities for each individual kid to ask questions, say opinions, and express preferences. The most effective classroom is one that is centered on diversity and brings students all together" (Participating Teacher's Written Reflection).

To enhance inclusive teaching, she stated that teachers should incorporate unbiased lesson plans, engage students' real-life experiences or knowledge in textbooks, and address diverse topics through varying instructional techniques. She held that it is educators' duty to make students feel proud of their heritage.

A special education teacher expressed the importance of respect and responsibility in teaching children with varying abilities and exceptionalities. $\mathrm{He}$ believed that inclusion is an incredible tool. He put,

"As a behavior therapist, I am always committed to promoting diversity through acknowledgment of different cultures. I am also committed to educating parents about how their own child is diverse in his or her own way. Whether their diversity shines through their sensory needs, their communication needs, or their academic abilities, they are part of an extremely diverse group of individuals who deserve to be treated with respect and valued as citizens who contribute to society in their own ways" (Participating Teacher's Written Reflection).

He highlighted that diversity exists in almost every facet of society, and it is of the utmost importance to not only acknowledge but also celebrate it.

One of the participating teachers who was teaching in a Catholic school 
expressed her tolerance and respect for different religious beliefs of her students. She noted that while individuals have religious freedom in the United States, not all religions are accepted equally. She shared,

"In the classroom of different types of schools, there is a large spectrum of religious beliefs and practices that may or may not be integrated into the day. I work in a Catholic school and each month the entire school community is to attend a mass service. To ensure that other religions are recognized in my classroom, I allow my students who are of different religious backgrounds to say a prayer in their religions. I would also say prayers in all religions to show students that all religions are accepted and welcomed in my classroom" (Participating Teacher's Written Reflection).

The teachers expressed their opinions on what teachers need to be aware of and how to create an inviting, safe, and inclusive classroom to promote students' learning. They indicated that it is important that teachers be cognizant of diversity in various aspects such as different races, cultures, languages, religious beliefs, and so forth in their classrooms and school buildings as each affects how students learn and behave. They believed that educators who are able to accept these differences, use them as students' strengths, and incorporate them in their classroom instruction will be successful in promoting multicultural education. They stressed that students learn best when they feel welcome, accepted and safe. One teacher expressed,

"Working in a multicultural classroom is like enjoying a delicious salad, filled with all different flavors, textures, colors, and sizes. Educators need to embrace the differences between students and acknowledge all the variety among the children in the classroom to make them all feel equal, loved, and special" (Participating Teacher's Written Reflection).

Becoming an inclusive teacher goes hand-in-hand with becoming a pro-active teacher. The participating teachers became convinced that in order to transform the culture of their classrooms and that of their schools, they need to become teachers as change agents. They emphasized that becoming pro-active and critical is a significant step towards reforming the school into a transformative learning community.

\section{Becoming pro-active teachers}

Data analysis reveals that becoming pro-active teachers is another most repetitive code. Again, this concept was highlighted by all of the 12 participating teachers. It appeared 52 times in the data, demonstrating the high premium participating teachers' put on the significance of becoming pro-active for promoting multicultural education.

The significant role of school culture was stressed by participating teachers, who held that creating a positive and empowering school culture cannot rely solely on administrators; teachers may also make a big contribution since their attitudes and behaviors directly affect students and have a significant impact on their classroom and school climate. 
Several teachers emphasized the vital role of communication among teachers. One of them stated that to promote multicultural education, it is highly necessary that teachers engage with each other in dialogue. She held, "Sincere communication can not only help avoid conflicts but contribute to better cooperation among colleagues. It is essential that all teaching staff is on the same page" (Participating Teacher's Written Reflection).

Working collaboratively with parents and communities was also highlighted by most teachers. One of them proposed a statement "involve to evolving" which basically explains that for students from different cultures to succeed in school, the teacher must first get involved and learn about the communities and cultures of the students so that the students can successfully grow and evolve into their full potential. She shared,

"In my view, there are three steps to make a student from a different background successful. First, school personnel need to reach out to parents rather than simply wait for parents to show up at a meeting; second, educators must know about the community and understand the cultures of the families; third, teachers should listen to parents and participate in the community to develop a range of teaching strategies" (Participating Teacher's Written Reflection).

In addition, the significance of teaching students following their aptitudes was noted by participating teachers. They held that teachers should develop interdisciplinary collaboration, implement effective co-teaching, and improve assessment strategies. One of them shared her ideas, "I always start the school year with a survey that helps me understand my students' diverse learning preferences and multiple intelligences. I stay close with the intervention specialist during lesson planning for enhancing students' education and make sure to use appropriate scaffolds to differentiate instruction, allowing for multiple pathways to meet students' different objectives" (Participating Teacher's Written Reflection).

One of the participating teachers expressed her determination to change the inequalities affecting the academic achievement of low-income students by integrating diversity into her teaching to create an equal and safe classroom environment. She presented her classroom social norms and activities this way,

"I will be mindful that classroom activities do not favor one group over another, pay attention to the leadership roles in small groups, and treat both sexes fairly in my classroom. I will do my best to deal with any bullying issues related to gender, language, ethnicity, and race. Besides, I will be vigilant in observing problems that are developing in my classroom, know my limitations, and seek help from the administration when necessary" (Participating Teacher's Written Reflection).

Similarly, an inner-city high school teacher designed a project lesson to create opportunities for her students to learn about other cultures, demonstrating her commitment as a change agent. She shared her project as follows,

"As an inner-city high school teacher, I discovered that my students have little access to any other culture beyond their communities. To introduce them to cultures and worlds with which they are unfamiliar, I 
designed a project lesson which consists of four parts-interview, presentation, reflection, and discussion-based on "four broad principles" put forward by Amthor and Roxas (2016)" (Participating Teacher's Written Reflection).

The participating teachers explicitly presented their ideas and action plans for becoming pro-active teachers and agents of change in their own classrooms and schools. They stressed that it is their responsibility to create classroom environments that celebrate diversity as a strength for teaching and learning.

\section{Importance of caring relationships in multicultural classrooms}

Apart from the above, data analysis suggests that the participating teachers also emphasized the importance of establishing caring relationships with students in multicultural classrooms, describing it as one of the most necessary elements for the implantation and promotion of multicultural education. It has been repeated 44 times; 10 of the 12 participating teachers talked about how caring relationships may help establish a harmonious, respectful, and moral classroom climate in which students are provided academic and emotional support to make meaning of their learning.

One of the teachers stated that to carry out multicultural education, his first goal is to create a classroom culture where all students feel safe, cared for, and loved. He stated that the main reason he loves teaching is that he wants to let his students know that there is a person who believes in them, loves them, and truly cares for them, especially when they don't have much love or support outside of school. He said, "Sincere love and care can do wonders" (Teacher's Reflection during Classroom Discussions).

Another teacher shared the strategies she would apply for building a strong relationship with her students' families. She planned to keep two checklists readiness for children with learning disabilities and their families checklist and environmental readiness checklist - which will provide different perspectives on self-supporting related to internal and external environments. She expressed that she wants her classroom to be full of friendship and care. She stated,

"This is what I want to do with my life: to care deeply for others and make everyone care for each other. I love my profession, which makes me truly happy. I love the students from complicated families who need someone to look at them with kindness and care; I love to see students implement a growing mindset and strive to meet expectations and goals with the help of my care and love; and I love to be the person to see the raw potential within a child" (Participating Teacher's Written Reflection).

Through experiencing a transformative learning community during the study, where they were free from fears of being judged by the instructor and their peers, the participating teachers became more sensitive to the students' diversity and voices. They realized and valued the caring relationships in their classrooms. In what follows we discuss the participating teachers' implementation plans. 


\section{Participating teachers' implementation plans}

From the limited understanding of multiculturalism at the beginning of the semester to their gradual in-depth study of cross-cultural activities, as participating teachers became more aware of who they are, they became more observers of their own perspectives and those of their colleagues. Believing that implementing multicultural education is an effective way to promote students' social and academic achievements, they became convinced that creating this type of learning environment is their moral and ethical obligation. In the final implementation paper, all the 12 participating teachers drew up their plans for the implementation of multicultural education in their classrooms, mainly focusing on the following three aspects: (1) attitudes towards teaching and students' learning; (2) selection and use of teaching materials; and (3) ways and activities to promote multicultural education.

\section{Attitudes towards teaching and students' learning}

In their future action plans, the first aspect emphasized by most participating teachers is their teaching attitudes and beliefs. They stated that the first thing they are to do is to get to know about their students and respect them as different individuals. They would assist the students to demonstrate their full potentials by providing them with a positive and caring environment and supporting their individual needs. The teachers noted that they would be transparent and authentic to their students, appreciate diversity, and create an inclusive classroom. They would also try to become acquainted with other cultures and become more aware of the cultural differences in nonverbal behaviors and gestures to serve the students effectively. They also mentioned that they would use appropriate scaffolds to differentiate instruction and modify their ways of teaching to suit the special requirements of individual students to facilitate their improvement.

A special education teacher stated that self-actualization would be the catalyst for implementing free growth. He claimed that specific personalized support for special students must be taken into action. He presented,

"I will guide my students to explore and celebrate exceptional talents, providing opportunities for them to share and demonstrate their unique knowledge and interests with peers in the general education classroom. But much like a parent removes the training wheels from their child's bike, my students, after appropriate instruction, will also be expected to take independent steps to discover what they are capable of accomplishing on their own. I strongly believe that a policy of freedom will result in the most comprehensive inclusion in society since students gain confidence and become empowered to direct their own future" (Participating Teacher's Implementation Paper).

The participating teachers also indicated that they would stay approachable for the students to talk to if they need someone to listen and help students think critically about sensitive issues such as racism, classism, and sexism. Further, the teachers stated that they are eager to learn and understand youth culture, get to know about different age groups to help students manage their age-related behaviors. They also highlighted constant reflection on themselves, their biases, attitudes, the practices and methods chosen, and what they bring into their 
classrooms.

\section{Selection and use of teaching materials}

Regarding teaching content and curricula, all the participating teachers expressed in their plans that they would try to include the experiences, cultures, and histories of diverse racial, ethnic, cultural, and religious groups, avoid mainstream-centric curricula, and reflect on curricula and teaching materials constantly, making sure not to blindly accept educational materials and policies that seem discriminatory, outdated, or unfair to students. For example, one of the teachers stated that she would introduce her students to learning materials created by people from diverse backgrounds, make the materials she teaches engaging and meaningful to her students, and include them in discussions so that they can interact with their learning.

A teacher of special education noted in her plan that special education teachers usually work with a small caseload of students who have math, science, social studies, language arts, and electives. Based on the characteristics of different subjects she planned to adopt different approaches to multicultural education. For mathematics and science, she would incorporate real-life scenarios into teaching and connect students' backgrounds to help improve their understanding and engagement with the materials. Current events would be included in social studies to emphasize contemporary social dynamics. She believed involving students in reading literature related to their upbringing and personal experiences in language arts class could significantly increase their engagement and interest and also boost their confidence in their reading abilities. When it came to teaching electives such as cooking, she shared that she would choose a different cultural background as the weekly focus, introducing the culture, food and the reasons why the food may be cooked in certain ways. She held that this would enable students from different cultures to integrate their kitchen and family traditions into the classroom, providing more multicultural opportunities.

\section{Ways and activities to promote multicultural education}

In their action plans, the participating teachers also included various ways and activities which may help facilitate multicultural education in their classrooms. To know more about students, some teachers planned to involve students in writing assignments, which cannot just help them understand students' thinking patterns and tendencies, but also helps students improve their writing skills. Also, they mentioned relating life struggles in the literature to students' real life, making them feel comfortable sharing their own stories and struggles of their family life. Further, using the Internet such as creating a "Google Classroom" to provide students with opportunities to share their unique immigration stories privately or publicly was also proposed.

To help students learn about other cultures, one of the teachers planned to link stories to a globe. She noted that for primary pupils, by showing them where they are on the globe, teachers can teach them different continents and describe how they are different from people living in other places speaking different languages, eating different foods, and practicing different religions. Several teachers noted that simulations and role-playing allow students to get out of their comfort zone and develop empathy with others, thus promoting higher- 
level engagement and understanding of how other cultural groups may differ from their own. Another teacher planned to organize eye-opening sessions on stereotypes, racism, sexism, and sexual orientations and to hold international or ethnic festivals or multi-cultural expositions where families can share their native cuisine, traditional costume, music, and dance. He also proposed inviting students' family members or guest lecturers from diverse backgrounds to the classroom to introduce their cultures and traditions to students. In his view, genuine interaction is the best approach and working collaboratively with parents and communities is an important step. One of the participating teachers planned to have students research and present different occurrences happening around the world, which would offer them opportunities to connect what they are learning with the real world and life. Similarly, another teacher stated in her plan that letting students research music of different cultures could be an extremely powerful tool to help them understand various traditions and ideas of people in multiple cultures.

One of the teachers stated that in order to ensure fair and meaningful learning opportunities for students, teachers need to apply different tools to enhance diversity, such as arranging classrooms accommodating different learners, diversifying images and content on bulletin boards, posters, and other visible materials, celebrating events and festivals of different cultures, imparting life skills to students through hands-on activities, etc. He noted that teachers need to "continuously raise their consciousness and stay current on issues of diversity. To help promote multicultural education, it is also important that teachers keep learning for their own personal and professional growth" (Participating Teacher's Implementation Paper).

\section{Discussion, Limitation and Recommendation}

Diverse students seeking education in the United States have different characteristics compared with their peers in the dominant society. It is demanded that multicultural education be implemented to help improve the academic achievements of those students from diverse cultural backgrounds (Banks, 1999; Apple, 2011). However, due to various factors, the implementation of multicultural education has been difficult. Multicultural education needs more insights and appreciations, especially from educators. The purpose of schooling is to cultivate the innate curiosity of human beings about the world around them and hand down the fundamental tools needed to fully explore and participate in it. However, the teaching strategies will not be truly effective unless the students have the stability of believing that they are accepted, safe, included, and have an advocate with their best interest at heart. This requires teachers to eliminate bias, tolerate and embrace diversity, and thus examine their own taken for granted perceptions and transform them into perspectives of multiculturalism.

The purpose of this study is to investigate how may a semester-long course on diversity provide in-service teachers opportunities to examine their prior perspectives on multicultural issues and transform their perspectives and practices. The findings suggest that participating teachers' reflection is an important component of teachers' professional development and 
transformation. In addition, the social norms of the classroom provided the participating teachers opportunities to emancipate themselves from fears of being evaluated by their classmates and/or their instructor. This situated learning environment afforded the teachers to critically reflect on who they are, how they feel, why they think and act the way they do, and what they should do as educators in the current era of diversity. These emancipatory critical reflections were crucial steps for teachers to understand their own biases and transform their perspectives and practices. As Grundy (1987) states,

"Moving from being uncritical to critical and from being ahistorical to a
subject who sees his/her work within a historical framework, require not
growth but transformation of consciousness. This is not a process of
steady development, but a transformation which might best be called
professionalization. This does not imply a spontaneous transformation
from constrained to liberated subjects. Rather, it is a process of
transformation in which knowledge and action are dialectically related
through the mediation of critical reflection" (Grundy, 1987, p.191).

Our research findings support Grundy's statement. The classroom discussions and activities invited the participating teachers to cross the boundary of their own familiar cultures and enter into unfamiliar territories. This crossing of boundary is a significant step towards changing their own classroom culture and hence impacting the current structure of their schools.

The limitation of this study is that it is context-specific and therefore cannot be generalized. Besides, the 15-week course was insufficient for follow-up observational studies on the participating teachers' implementation of their plans which requires further reflection, adjustment, and evaluation. Therefore, future research is needed on teachers' practical implementation of multicultural education in their classrooms and school buildings. We also recommend research on collaboration among emerging teachers, experienced teachers, and university professors for planning, instruction, and assessment relative to multicultural education.

\section{Conclusion}

In this study, we examined 12 in-service teachers' perspectives on multicultural issues. We described the transformation of their perspectives and practices as they took a semester-long course on diversity. The findings of the study can be useful and beneficial for other teachers and scholars relative to teaching, learning and educational research in similar contexts. Teachers' professional development, establishing classroom social norms conducive to multicultural classrooms, critical reflections, and building a caring relationship with students are essential components of educational equity. Do existing school structures provide teachers with opportunities to engage in meaningful discussions and dialogues regarding multicultural issues? Do current school curricula include all students' cultural and social activities? From our perspective, reflections and discussions regarding the above questions among teachers are vital for creating learning opportunities for all students in multicultural school settings. Reconstructing current school structures and curricula is a necessary step towards inclusive, democratic, open, and emancipatory education. 
For our participating teachers, moving from a passive member to a pro-active member of their school community, moving from being non-confrontational to a critical teacher was a dialectic process. Grundy (1987) calls this process "transformation of consciousness". This transformation is non-linear and complex, and it requires an on-going professional development and support. Future research may focus on an on-going partnership between higher education institutions and public schools for sustaining this culture of "professionalization".

\section{About the Authors:}

Roland G. Pourdavood is a professor of mathematics education at Cleveland State University, Department of Teacher Education. His research interests include mathematics teachers' dialogue and reflection for transformation and school reform. In addition, he focuses on cultural diversity, socio-cultural aspects of education, and emancipatory action research for personal and social praxis.

Meng Yan is a second-year doctoral student of learning and development in urban education at Cleveland State University. Her current research interests include curriculum development and instruction, teacherstudent relationship, motivation, parenting style and student well-being. She is also interested in second language acquisition, bilingualism, and the relationship between language and thought.

\section{References}

Alismail, H. A. (2016). Multicultural education: Teachers' perceptions and preparation. Journal of Education and Practice, 7(11), 139-146.

Ameny-Dixon, G. M. (2004). Why multicultural education is more important in higher education now than ever: A global perspective. International Journal of Scholarly Academic Intellectual Diversity, 8(1), 1-9.

Amthor, R. F., \& Roxas, K. (2016). Multicultural education and newcomer youth: Reimagining a more inclusive vision for immigrant and refugee students. Educational Studies, 52(2), 155-176. doi:10.1080/00131946.2016.1142992

Apple, M. W. (2011). Global crises, social justice, and teacher education. Journal of Teacher Education, 62(2), 222-234. doi:10.1177/0022487110385428

Apple, M. W. (2017). The struggle for democracy in critical education. RevistaeCurriculum. 15, 894. doi:10.23925/1809-3876.

Apple, M. W. (2018). The critical divide: Knowledge about the curriculum and the concrete problems of curriculum policy and practice. Nordic Journal of Studies in Educational Policy, 4(2), 63-66. doi:10.1080/20020317.2018.1492692

Apple, M., \& Beane, J. A. (2007). Democratic schools: Lessons in powerful education. Portsmouth, NH: Heinemann.

$\mathrm{Au}, \mathrm{K}$. H. (2011). Literacy achievement and diversity: Keys to success for students, teachers, and schools. Multicultural Education Series. New York, NY: Teachers College Press.

Banks, J. A. (1989). Approaches to multicultural curriculum reform. Trotter Review, 3(3), 5-33. doi:10.4135/9781452218533.n491

Banks, J. A. (1993). Multicultural education: Development, dimensions, and challenges. The Phi Delta Kappan, 75(1), 22-28. doi:10.2307/1167339 
Banks, J. A. (1994). An introduction to multicultural education. Boston, MA: Allyn \& Bacon.

Banks, J. A. (1999). An introduction to multicultural education. (2nd Ed.). Boston: Allyn \& Bacon.

Banks, J. A. (2001). Multicultural education: Characteristics and goals. In J. A. Banks \& C. A. M. Banks (Eds.), Multicultural education: Issues and perspectives (pp. 15-30). New York, NY: John Wily \& Sons Inc.

Banks, J. A. (2004). Teaching for social justice, diversity, and citizenship in a global world. In The Educational Forum, 68(4), 296-305. Taylor \& Francis Group. doi:10.1080/00131720408984645

Banks, J. A. (2013). The construction and historical development of multicultural education, 1962-2012, Theory into Practice, 52(1), 73-82. doi: 10.1080/00405841.2013.795444

Banks, J. A., \& Banks, C. A. M. G. (1995). Handbook of research on multicultural education. New York, NY: Macmillan Pub.

Banks, J. A., \& Banks, C. A. M. (2001). Multicultural education: Issues and perspectives (4th Ed.). Boston: Allyn \& Bacon.

Bruner, J. S. (1996). The culture of education. Boston: Harvard University Press.

Burton, M. (2012). What is math? Exploring the perception of elementary pre-service teachers. Issues in the Undergraduate Mathematics Preparation of School Teachers, 5, $1-13$.

Charmaz, K. (2001). Grounded theory: Methodology and theory construction. doi:10.1016/b0-08-043076-7/00775-0

Cobb, P. (1994). Where is mind? Constructivist and sociocultural perspectives on mathematical development. Educational Researcher, 23(7), 13-20. doi:10.2307/1176934

Cobb, P., Wood, T., \& Yackel, E. (1990). Classroom as learning environments for teachers and researchers. Journal for Research in Mathematics Education, Monograph, 4, 125146 \& 195-210. doi:10.2307/749917

Cobb, P., \& Yachel, E. (1996). Constructivist, emergent, and sociocultural perspectives in the context of developmental research. Educational Psychologist, 31(3/4), 175-190. doi:10.1080/00461520.1996.9653265

Creswell, J. W., \& Poth, C. N. (2018). Qualitative inquiry and research design: Choosing among five approaches. Los Angeles, CA: Sage.

Darder, A. (1991). Cultural and power in the classroom: A critical foundation for bicultural education. Westport, CT: Bergin \& Garvey.

Delpit, L. D. (1992). Education in a multicultural society: Our future's greatest challenge. The Journal of Negro Education, 61(3), 237-249. doi:10.2307/2295245.

D'Souza, D. (1991). Illiberal education: The politics of race and sex on campus. Simon and Schuster.

Ford, D. Y. (2014). Why education must be multicultural: Addressing a few misperceptions with counterarguments. Gifted Child Today, 37(1), 59-62. doi:10.1177/1076217513512304

Freire, P. (2000). Pedagogy of the oppressed. New York, NY: Continuum.

Freire, P., \& Freire, A. M. A. (1994). Pedagogy of hope: Reliving pedagogy of the oppressed. New York: Continuum.

Garcia, J., \& Pugh, S. (1992). Multicultural education in teacher preparation programs. Phi Delta Kappan, 74(3), 214-219.

Gay, G. (1994). At the essence of learning: Multicultural education. Kappa Delta Pi.

Gay, G. (2003). The importance of multicultural education. Educational Leadership. 61(4), 30-35.

Gollnick, D. M., \& Chinn, P. C. (2017). Multicultural education in a pluralistic society. Boston, MA: Pearson.

Grant, K. S. L., Lee, V. J., \& Lyttle, C. F. (2018). White pre-service and in-service teachers' 
engagement with multicultural content in online courses. Multicultural Education, 26(1), 17-23.

Grundy, S. (1987). Curriculum: Product or praxis. New York: The Falmer Press.

Guba, E. G., \& Lincoln, Y. S. (1989). Fourth generation evaluation. Newbury Park, CA: Sage.

Guba, E. G., \& Lincoln, Y. S. (1994). Comparing paradigm in qualitative research. In N. K. Denzin \& Y. S. Lincoln (Eds.), Handbook of Qualitative Research (105-117). Thousand Oaks, CA: Sage.

Gutstein, E. (2006a). Reading and writing the world with mathematics: Toward a pedagogy for social justice. doi: 10.4324/9780203112946.

Gutstein, E., \& Peterson, B. (2013). Rethinking mathematics: Teaching social justice by the numbers. Milwaukee, Wisconsin: Rethinking Schools.

Hays, D. G., \& Singh, A. A. (2012). Qualitative inquiry in clinical and educational settings. NY: The Guilford Press. doi:10.1111/j.1467-8535.2012.01317_6.x

Hill, H. C., \& Ball, D. L. (2004). Learning mathematics for teaching: Results from California's mathematics professional development institutes. Journal for Research in Mathematics Education, 35, 330-351. doi:10.2307/30034819

Hrabowski III, F. A., \& Robbi, J. (2002). The benefits of correctional education. Journal of Correctional Education, 53(3), 96-99.

Hussar, W. J., \& Bailey, T. M. (2013). Projections of education statistics to 2021. NCES 2013-008. National Center for Education Statistics.

Ladson-Billings, G. (1994). What we can learn from multicultural education research. Educational Leadership, 51(8), 22-26.

Ladson-Billings, G. (1995a). Toward a theory of culturally relevant pedagogy. American Educational Research Journal, 32(3), 465-491. doi:10.3102/00028312032003465

Ladson-Billings, G. (1995b). But that's just good teaching! The case for culturally relevant pedagogy. Theory into Practice, 34(3), 159-165. doi:10.1080/00405849509543675

Le Roux, A., \& Connors, J. (2001). A cross-cultural study into loneliness amongst university students. South African Journal of Psychology, 31(2), 46-52. doi:10.1177/008124630103100206

Nieto, S. (2000a). Affirming diversity: The sociopolitical context of multicultural education. New York: Longman.

Nieto, S. (2000b). Placing equity front and center: Some thoughts on transforming teacher education for a new century. Journal of Teacher Education, 51(3), 180-187. doi:10.1177/0022487100051003004

Noddings, N. (1992). The challenge to care in schools. New York, NY: Teachers College Press. doi:10.3726/978-1-4539-1735-0/37

Noddings, N. (1995). Teaching themes of care. Phi Delta Kappan, 76, 675-675.

Noddings, N. (2008). Caring and moral education. Handbook of Moral and Character Education, 161-174.

Noddings, N. (2012). The caring relation in teaching. Oxford Review of Education, 38(6), 771-781. doi:10.1080/03054985.2012.745047

Moll, L. C., Amanti, C., Neff, D., \& Gonzalez, N. (1992). Funds of knowledge for teaching: Using a qualitative approach to connect homes and classrooms. Theory into Practice, 31(2), 132-141. doi:10.1080/00405849209543534

Salako, E., Eze, I., \& Adu, E. (2013). Effects of cooperative learning on junior secondary school students' knowledge and attitudes to multicultural education concepts in social studies. Education, 133(3), 303-309.

Saldaña, J. (2013). The coding manual for qualitative researchers. (2nd Ed.). Los Angeles, CA: SAGE Publications.

Shulman, L. S. (1986). Those who understand: Knowledge growth in teaching. Educational Researcher, 15(2), 4-14. doi:10.3102/0013189x015002004

Sleeter, C. E. (1994). White racism. Multicultural Education, 1(4), 5-8. 
Sleeter, C. E. (2001). Preparing teachers for culturally diverse schools: Research and the overwhelming presence of whiteness. Journal of Teacher Education, 52(2), 94-106. doi:10.1177/0022487101052002002

Sleeter, C., \& Grant, C. (1999). Making choices for multicultural education: Five approaches to race, class, and gender (3rd Ed.). Upper Saddle River, NJ: Merrill.

Smith, T. B., Constantine, M. G., Dunn, T. W., Dinehart, J. M., \& Montoya, J. A. (2006). Multicultural education in the mental health professions: A meta-analytic review. Journal of Counseling Psychology, 53(1), 132-145.

Snyder, T. D., de Brey, C., \& Dillow, S. A. (2016). Digest of Education Statistics 2014 (NCES 2016-006). National Center for Education Statistics, Institute of Education Sciences, U.S. Department of Education. Washington, DC. Retrieved from https://files.eric.ed.gov/fulltext/ED565675.pdf

Sue, D. W., Arredondo, P., \& McDavis, R. J. (1992). Multicultural counseling competencies and standards: A call to the profession. Journal of Counseling and Development, 70(4), 477-486. doi:10.1002/j.2161-1912.1992.tb00563.x

Villegas, A. M., \& Lucas, T. (2002). Preparing culturally responsive teachers: Rethinking the curriculum. Journal of Teacher Education, 53(1), 20-32. doi: $10.1177 / 0022487102053001003$

Wlodkowski, R. J., \& Ginsberg, M. B. (1995). A framework for culturally responsive teaching. Educational Leadership, 53(1), 17-21. 